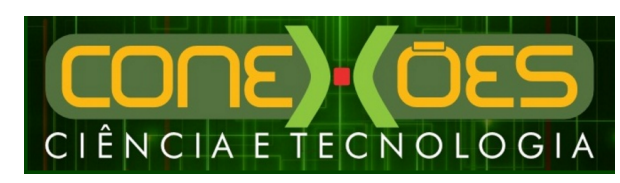

\title{
O PANORAMA DA REDE HOTELEIRA MIDSCALE DA PRAIA DE IRACEMA EM FORTALEZA-CE PARA O PÚBLICO LGBT
}

\author{
DANiel FERreira MEndonÇA, Júlio César FERreira Lima \\ Instituto Federal de Educação, Ciência e Tecnologia do Ceará \\ <leowyvern.x@gmail.com>, <julioepedrita@gmail.com>
}

DOI: 10.21439/conexoes.v11i5.1256

\begin{abstract}
Resumo. Este artigo objetivou analisar o posicionamento dos hotéis da Praia de Iracema em Fortaleza CE em relação ao marketing aplicado junto ao público LGBT. Por isso, buscou-se precisar o número de hotéis que se enquadravam como "gay friendly" e identificar fatores que pudessem dificultar o investimento do setor hoteleiro no segmento LGBT. Tratou-se de uma pesquisa analítica por meio de um estudo de caso realizado em 2016 com 14 hotéis de categoria midscale situados em um bairro turístico da cidade de Fortaleza. Utilizaram-se objetivos descritivos com a aplicação de método indutivo, objetivando uma compreensão generalizada de uma segmentação do mercado turístico partindo-se de fatos particulares. Foram realizadas pesquisas bibliográfica e documental como embasamento teórico, englobando estudos sobre o fenômeno turístico na cidade de Fortaleza, uma visão geral sobre segmentação de mercado e uma discussão sobre o segmento LGBT de modo generalizado e dentro da hotelaria. Ao final, verificou-se que a rede hoteleira em questão não se propõe a trabalhar com o mercado de maneira segmentada e não tem o conhecimento necessário a respeito do potencial de consumo do público LGBT. Concluiu-se que existe desinteresse da parte dos hotéis midscale pesquisados em investir na captação deste nicho de mercado pela simples preferência pela padronização do atendimento.
\end{abstract}

Palavras-chaves: Turismo; Segmentação Turística; LGBT; Hotelaria.

\begin{abstract}
This article aimed to analyze the position of Praia de Iracema hotels in Fortaleza - CE in relation to the marketing applied to the LGBT public. Therefore, it was necessary to specify the number of hotels that were classified as "gay friendly" and to identify factors that could hinder the investment of the hotel sector in the LGBT segment. This is an analytical research through a case study carried out in 2016 with 14 midscale hotels located in a tourist district in the city of Fortaleza. Descriptive objectives were used with the application of the inductive method, aiming at a generalized understanding of a segmentation of the tourist market starting from particular facts. Bibliographical and documentary research was carried out as a theoretical basis, encompassing studies on the phenomenon of tourism in the city of Fortaleza, an overview on market segmentation and a discussion about the LGBT segment in general and within the hotel industry. In the end, it was verified that the hotel network does not intend to work with the market in a segmented way and does not have the necessary knowledge regarding the potential of consumption of the LGBT public. It was concluded that there is a lack of interest on the part of the surveyed midscale hotels in investing in the capture of this market niche by the simple preference for the standardization of the service.
\end{abstract}

Keywords: Tourism; Tourist Segmentation; LGBT; Hospitality.

\section{INTRODUÇÃO}

A palavra que representa este trabalho de modo mais eficiente é "diversidade". A sociedade contemporânea mundial evidencia várias facetas por via de uma pluralidade de credos, etnias, culturas e linguajares. A popu- lação brasileira não podia ser diferente disso e expressa uma infinidade de jeitos de expressão cultural, tão distintos entre si que é como se existissem vários outros "Brasis" dentro de um só. Esse senso comum é reforçado em Hartmut Sangmeister e Steckbauer (2007), 
quando acentuam que o maior país da América do Sul é caracterizado por um caleidoscópio cultural, religioso, gastronômico e artístico, dentre outros aspectos.

Inserido nessa realidade multifacetada, está o mercado econômico atual que, por sua vez, é um meio competitivo, exigindo cada vez mais das empresas que medidas inovadoras sejam tomadas, sob o risco de que essas organizações sejam expurgadas da corrida empresarial. (FURBINO, 2010) defende que a busca por melhoria contínua garante a sobrevivência de qualquer organização e essa deve ser uma meta presente nos objetivos das empresas.

Nesse quadro, a qualificação profissional também é um diferencial e, mais que isso, é uma exigência do mercado. Os motivos principais para isso são a forte concorrência e a globalização econômica. Mota (2011) declara que tanto o turismo quanto a hotelaria exige mão de obra qualificada para estabilização do fluxo turístico do mundo globalizado atual.

Esse fato ocorre igualmente em variados setores do mercado, inclusive no de perfil turístico, onde o contato com a diversidade cultural é ainda mais explícito. De acordo com Tanke (2005, p.397) "cada vez mais o sucesso ou o fracasso de uma organização de hospitalidade é determinado por sua habilidade, para compreender a dinâmica do pluralismo cultural e valorizar plenamente o local de trabalho de diversidade cultural."Com suporte nessas afirmações, pode-se verificar que a qualificação profissional de uma empresa, quando embasada no conceito diversidade cultural, é fator significativo para o êxito de um estabelecimento comercial dentro do mercado turístico.

Uma estratégia de marketing para atender esse público cada vez mais diversificado é a divisão de um grupo grande de pessoas em categorias menores, mas com características semelhantes, a chamada segmentação de mercado. Diversos autores já discorreram a respeito desse tema. Kotler (2000 p. 278) define segmento de mercado como "um grande grupo identificado a partir de suas preferências, poder de compra, localização geográfica, atitudes de compra e hábitos de compra similares". Cobra (2009, p. 123), por sua vez, acentua que a "segmentação de mercado é a ação de identificar e classificar grupos distintos de compradores que apresentem comportamentos de compra relativamente homogêneos". O processo de segmentação se realiza sem maiores complicações na visão de Tuleski (2009), uma vez que devido à multiplicidade de características dos consumidores, é óbvio que um mesmo produto não será desejado por todos da mesma forma. Em consequência, deve-se haver a separação de grupos de consumidores por semelhanças, ocasionando assim uma relação co- mercial mais homogênea e fácil de lidar.

No que tange ao mercado turístico, essa segmentação se faz igualmente meritória, já que o setor também lida com diversidade cultural, religiosa, étnica e social. O Ministério do Turismo do Brasil (MTUR. 2010) aposta em tendências de consumo como oportunidades de valorização das diversidades e particularidades do país, estimulando uma segmentação estratégica para estruturar e comercializar destinos e roteiros turísticos.

Como se pode perceber, dividir um público em segmentos e trabalhar cada particularidade separadamente é uma prática comercial muitas vezes bem-sucedida, uma vez que permite ao empreendedor ter uma visão específica de seu público-alvo e até mesmo se especializar em um determinado público apenas.

O segmento GLS (Gays, Lésbicas e Simpatizantes) ou LGBT (Lésbicas, Gays, Bissexuais, Travestis e Transexuais) com o chamado pink money - expressão que faz referência ao poder aquisitivo dos gays - é um desses públicos específicos a serem explorados e é o segmento que será alvo desse estudo. Nucci (2014) afirma que a expressão monetária surgiu porque esse público é normalmente formado por pessoas exigentes quanto à qualidade dos produtos e serviços consumidos.

Cabe aqui breve explanação a respeito das abreviaturas utilizadas para dar referência a esse público. A abreviação LGBT é em alguns casos grafada LGBTT e ambas são uma atualização da sigla inicial GLBT - Gays, Lésbicas, Bissexuais e Transgêneros - a mudança se deu para valorizar o público femining ${ }^{1}$ mediante a utilização do termo lésbica para iniciar a abreviação. Essa denominação é atualmente utilizada quando a intenção é se referir aos indivíduos propriamente ditos desse grupo e carrega um caráter político-social, representativo de um movimento que luta pelos direitos de seus membros, pessoas que sofrem preconceito e discriminação simplesmente em virtude da sua orientação sexual. O conjunto GLS² abreviação para Gays, Lésbicas e Simpatizantes, é comumente utilizado para se referir a estabelecimentos comerciais, espaços e serviços voltados para o público LGBT. Com efeito, podemse denominar bares GLS, boates GLS, hotéis GLS etc. Segundo Fischer (2007), GLBTT é a sigla utilizada para falar de direitos dos gays, lésbicas, bissexuais e trans-

\footnotetext{
${ }^{1}$ De acordo com a $1^{\text {a }}$ Conferência Nacional GLBT, realizada em Brasília, no período de 5 a 8 de junho de 2008. (Anais da Conferência nacional de Gays, Lésbicas, Bisexuais, Travestis e Transexuais, 2008)

${ }^{2}$ De acordo com Facchini (2005), a origem de GLS está ligada ao nome de André Fischer, responsável pelo Festival Mix Brasil de Diversidade Sexual, uma mostra de cinema, festas e exposições voltadas para o público LGBT. O termo ganhou força e é utilizado até hoje pelos brasileiros.
} 
gêneros; enquanto que a sigla GLS é um termo alusivo ao mercado.

Justifica-se essa pesquisa pela existência, na cidade de Fortaleza, de atividades voltadas ao público LGBT como boates, barracas de praias, bares e saunas assumidamente gays. A questão principal, pois, deste trabalho é a análise de parte do quadro hoteleiro voltado ao mesmo público. Para essa exposição, as seguintes questões de pesquisa foram levantadas: os hotéis midscale ${ }^{3}$ da Praia de Iracema estão cientes da possibilidade de lucro ao investir no segmento LGBT?; há hotéis que se intitulem "gay friendly" 4 na Praia de Iracema?; e, que fatores podem dificultar o investimento dos hotéis no segmento LGBT?

O objetivo geral do trabalho se constituiu, portanto, em analisar o posicionamento dos hotéis da Praia de Iracema em Fortaleza - CE em relação ao marketing aplicado junto ao público LGBT. Essa análise acontece por meio de dois objetivos específicos, a saber, precisar o número de hotéis midscale que se enquadram como "gay friendly"; e identificar fatores que possam dificultar o investimento do setor hoteleiro no segmento LGBT.

\section{METODOLOGIA}

Essa seção evidencia os componentes da trajetória da pesquisa, que são os procedimentos e pressupostos metodológicos levados em conta para levantamento, organização e mostra dos resultados de um determinado problema.

Pesquisas relativas ao tema em estudo ainda são escassas. Foi possível realizar inicialmente uma busca bibliográfica em livros, monografias, artigos, reportagens e entrevistas que abordavam essa temática, embora de modo ainda limitado. Também foram utilizados materiais das palestras da Expobusiness-LGBT Mercosu[5

\footnotetext{
${ }^{3} \mathrm{~A}$ categoria midscale corresponde aos anteriormente denominados hotéis de 3 e 4 estrelas. Segundo informações da Secretaria de Turismo de Fortaleza, os hotéis da cidade de Fortaleza não possuem categorização por estrelas, uma vez que essa forma de classificação já não é mais utilizada desde a publicação da Portaria ${ }^{\circ} 17$ do Ministério do Turismo de 12 fev. 2010, que tornou sem efeito o Sistema de Classificação dos Meios de Hospedagem que havia à época. Atualmente, as bandeiras hoteleiras estão agrupadas em quatro categorias principais: budget (supereconômico), economy (econômico), midscale/upscale e upperscale (hotéis de luxo). (Nota dos autores)

4"Gay friendly" é a expressão utilizada para designar estabelecimentos comerciais que são amigáveis com o público LGBT, sendo um ambiente onde não vai haver discriminação em decorrência da orientação sexual dos clientes. (Nota dos autores)

${ }^{5}$ A Expobusiness-LGBT Mercosul é uma feira de negócios focada em produtos e serviços orientados ao público específico LGBT, para incrementar os serviços de empresas e ao mesmo tempo prepará-las para atender da melhor forma este segmento. (Nota dos Autores)
}

gentilmente cedido pelos organizadores, onde se promoveram discussões sobre a temática LGBT, ensejando oportunidades para empresas em geral investirem nesse segmento.

Foi realizada também uma pesquisa de campo junto à rede hoteleira do bairro Praia de Iracema da cidade de Fortaleza - Ceará. O campo de extração foi delimitado a hotéis de categoria midscale. A pesquisa foi realizada presencialmente, durante o primeiro semestre do ano de 2016, consultando preferencialmente o setor de recepção e/ou reservas do hotel.

$\mathrm{O}$ instrumento de pesquisa para a coleta de dados foi um questionário com nove questões. Optou-se por questões fechadas de múltipla escolha, permitindo assim, maior eficiência na comparação dos indicadores dos entrevistados. Cada uma das nove perguntas era composta por três ou quatro alternativas de resposta. Ao todo, foram entregues 20 questionários de acordo com a lista de hotéis categoria midscale fornecida pela Secretaria de Turismo de Fortaleza. Apenas 14 estabelecimentos devolveram os questionários preenchidos, o que correspondeu a 70\% do universo da pesquisa.

Quanto aos objetivos, a pesquisa é classificada como descritiva, pois identificou, registrou e analisou o comportamento de hotéis em relação ao público LGBT. Sendo assim, posteriormente, foi possível estabelecer um paralelo entre as teorias sobre segmentação de mercado turístico e a prática da realidade estudada.

O método científico utilizado foi o indutivo, pois o estudo apresenta a observação de fenômenos particulares de cada hotel, registrados nos questionários aplicados, para que seja plausível um entendimento genérico sobre os pontos centrais do estudo.

\section{O FENÔMENO TURÍSTICO NA CIDADE DE FORTALEZA}

É impossível referir-se a algum assunto relacionado à hotelaria sem ter que, primeiramente, falar da atividade econômica que a sustenta - o Turismo. O Brasil, segundo dados do MTur (2015), foi o país que liderou a lista das nações sul-americanas no turismo receptivo em 2014, amparado pela Copa do Mundo, quando chegou a receber mais de um milhão de visitantes Atualmente, o MTur subsidia mais de cinco mil obras em andamento e já computa investimentos da ordem de $\mathrm{R} \$ 8,8$ bilhões na implantação de sinalização turística, urbanização de orlas, construção de centros de convenções, entre outras (MTUR, 2016, 7

\footnotetext{
${ }^{6}$ Matéria intitulada "Turismo mundial registra recorde de viajantes em 2014". (site do MTur)

${ }^{7}$ Matéria intitulada "Turismo entrega 88 obras de infraestrutura no Ceará em 2016”. (site do MTur)
} 
Segundo a pesquisa sobre investimento em obras para o turismo, o MTur foi o responsável pelo repasse de R 499 milhões investidos em 1052 obras em 24 estados brasileiros e entregues em 2016. Do total de obras, 88 estão no Estado do Ceará; número igual ao do Estado do Paraná e inferior apenas aos números dos Estados de São Paulo e do Rio Grande do Sul, com 141 e 106 obras, respectivamente.

No Ceará, o investimento do Ministério do Turismo foi de $\mathrm{R} \$ 49,9$ milhões, com uma contrapartida de $\mathrm{R} \$$ 4,6 milhões de governos municipais. Entre as obras entregues em 2016 estão a pavimentação asfáltica em Juazeiro do Norte, a construção do Mercado do Peixe e a reforma do Paço Municipal, ambas as obras em Fortaleza (MTUR, 2016, 8

Fortaleza, capital do Estado do Ceará, é uma cidade que desperta muito o interesse de estrangeiros e de visitantes de outras partes do País, e os motivos são bem conhecidos: as praias, o sol que brilha forte durante a maior parte do ano, a vida noturna e a gastronomia, entre outros aspectos. Tamanho interesse faz com que a cidade seja um dos mais procurados destinos turísticos do Brasil, como se constata a seguir no quadro 1 em dados estatísticos da Fundação Comissão de Turismo Integrado do Nordeste (FUNDAÇÃO CTI/NE, 2014) que mostram o fluxo turístico nas capitais nordestinas. No período entre os anos de 2006 e 2014, Fortaleza figurou em terceiro lugar na preferência de visitantes, estando atrás apenas de Salvador e Recife.

\begin{tabular}{|l|r|r|r|r|r|c|c|c|c|}
\hline \multirow{2}{*}{ Capitais } & \multicolumn{7}{|c|}{ Fluxo turístico nas capitais do NE (mil) } \\
\cline { 2 - 10 } & $\mathbf{2 0 0 6}$ & $\mathbf{2 0 0 7}$ & $\mathbf{2 0 0 8}$ & $\mathbf{2 0 0 9}$ & $\mathbf{2 0 1 0}$ & $\mathbf{2 0 1 1}$ & $\mathbf{2 0 1 2}$ & $\mathbf{2 0 1 3}$ & $\mathbf{2 0 1 4}$ \\
\hline $\begin{array}{l}\text { Salvador } \\
(\mathrm{BA}) * *\end{array}$ & 2.490 & 2.616 & 2.620 & 2.848 & 3.047 & 3.267 & 3.522 & 3.796 & 4.119 \\
\hline $\begin{array}{l}\text { Recife } \\
(\mathrm{PE})\end{array}$ & 2.083 & 2.128 & 2.214 & 2.297 & 2.479 & 2.648 & 2.774 & 2.917 & 3.093 \\
\hline $\begin{array}{l}\text { Fortaleza } \\
\text { (CE) }\end{array}$ & 2.062 & 2.079 & 2.178 & 2.467 & 2.692 & 2.848 & 2.995 & 3.141 & 3.262 \\
\hline $\begin{array}{l}\text { Total no } \\
\text { Nordeste }\end{array}$ & $\mathbf{1 1 . 4 6 5}$ & $\mathbf{1 1 . 8 2 6}$ & $\mathbf{1 2 . 1 3 4}$ & $\mathbf{1 3 . 1 7 3}$ & $\mathbf{1 4 . 3 7 6}$ & $\mathbf{1 5 . 3 1 7}$ & $\mathbf{1 5 . 2 3 9}$ & $\mathbf{1 7 . 0 9 3}$ & $\mathbf{1 7 . 9 8 9}$ \\
\hline
\end{tabular}

Quadro 1: Fonte: Adaptado do Relatório de Competitividade da Fundação CTI/NE.

Obs.: (**) 2006 a 2009: dados preliminares.

Segundo um levantamento da plataforma de turismo Trip Advisor (O POVO, 2014), Fortaleza foi o quarto destino mais procurado pelos brasileiros em 2016, ficando atrás de São Paulo, Rio de Janeiro e Gramado, no Estado do Rio Grande do Sul. Comparando com os dados de 2015, a Capital cearense subiu uma posição. Segundo uma pesquisa de intenção de viagens realizada

\footnotetext{
${ }^{8}$ Matéria intitulada "Turismo entrega 88 obras de infraestrutura no Ceará em 2016” (site do MTur)
}

pelo MTur (2016 a região Nordeste do País continuará na liderança da lista das regiões mais desejadas pelos brasileiros (41\%) no ano de 2017.

Internacionalmente falando, Fortaleza denota aumento anual no número de visitantes estrangeiros. Comparando-se dados de 2012 com o que foi verificado em 2014, houve um crescimento de cerca de $20 \%$ na quantidade de turistas advindos do exterior. Dados da Empresa Brasileira de Infraestrutura Aeroportuária (Infraero) apontam que em 2015 houve o desembarque de 31.398 estrangeiros e nos quatro primeiros meses de 2016 foram 31.76110

Os números comprovam a importância tanto do Estado do Ceará, como sua capital, principal portão de entrada, no cenário turístico do País. Isto posto, constatase uma participação significativa dessas localidades no turismo do Brasil, por meio de investimentos variados para o desenvolvimento da atividade.

\section{O SETOR HOTELEIRO DE FORTALEZA E SUAS TÉCNICAS DE MARKETING - A SEG- MENTAÇÃO DE MERCADO}

A hotelaria, setor onde se põe em prática os desígnios da hospitalidade, é um serviço indispensável para a consumação da atividade turística. Freitas e Silva assinalam que:

\footnotetext{
Como segmento integrante e indispensável da cadeia produtiva do turismo, os meios de hospedagem tornamse estruturas singulares para a formação do conceito de turismo, considerando-se que esta atividade se desenvolve no espaço e que os elementos de transporte, hospedagem e alimentação formam os serviços mínimos, para que o turismo possa existir. (FREITAS; SILVA 2011. p.92)
}

Essa importância do setor hoteleiro se reflete no fato de que, apesar do atual momento de crise econômica em que se encontra o País, ainda há espaço para investimentos na área. De acordo com Calfat (2014 11 o ramo hoteleiro vai de encontro à crise econômica brasileira atual, impulsionado por eventos esportivos, culturais e empresariais, como também com a interiorização do turismo no Brasil.

\footnotetext{
${ }^{9}$ Nordeste lidera escolha do brasileiro para viagens."(site do MTur)

${ }^{10}$ Conforme o site da Prefeitura de Fortaleza (2016), em matéria intitulada "Cresce o número de turistas estrangeiros em Fortaleza."

${ }^{11}$ Caio Calfat - sócio-diretor da Real Estate Consulting, consultoria que atua no desenvolvimento de empreendimentos imobiliários e hoteleiros desde 1996. Calfat também ocupa o posto de vice-presidente do Sindicato da Habitação de São Paulo (Secovi-SP) para Assuntos Turísticos e Imobiliários. (Nota dos autores)
} 
O setor hoteleiro de Fortaleza acompanha, principalmente dentro da área geográfica desta pesquisa, de maneira diretamente proporcional, o crescimento do turismo exposto no item anterior. Segundo pesquisa publicada pelo (IBGE, 2011), Fortaleza é a quinta capital do Brasil e a segunda do Nordeste em capacidade de hospedagem, incluindo hotéis de todos os portes, e ainda albergues, pousadas e motéis, constituindo-se de 92 hotéis, 12 apart-hotéis, 60 pousadas, 110 motéis, três pensões de hospedagem, dois albergues turísticos e um classificado como dormitório/hospedaria, levando em consideração as categorias de luxo a simples.

Apesar dessa realidade promissora, um dos principais problemas em todo o setor hoteleiro é a sazonalidade, ou seja, os altos e baixos na taxa de ocupaçãd ${ }^{12}$ que ocorrem em certos períodos do ano e que podem comprometer, e muito, a lucratividade do hotel. Segundo Cunha(1997, p.189), a sazonalidade pode ser definida pela "distribuição da procura por destinos turísticos, ao longo do ano, de forma desigual, provocando uma concentração em alguns meses mais do que outros, e deriva de fatores climáticos, geográficos, demográficos, econômicos e psicossociais". Yaari (2010), por sua vez, exemplifica a sazonalidade hoteleira com a variação do clima, os períodos de férias escolares e até pela ineficácia no planejamento e aplicação de ações estratégicas para combater esse problema.

A atividade hoteleira é, pois, um ramo em que há uma oscilação na lucratividade de acordo com o período do ano, em razão dessa mudança sazonal nas taxas de ocupação. Em hotelaria, costuma-se definir esses períodos como alta estação e baixa estação.

A temporada de alta estação compreende o período do ano em que ocorre um aumento na taxa de ocupação de um meio de hospedagem. No Brasil, normalmente, esses períodos ocorrem durante as férias escolares, feriados prolongados como o carnaval e as festividades de fim de ano. É comum, no decorrer desses períodos, que os meios de hospedagem exprimam um acréscimo significativo nos preços de suas diárias. Esse é o momento em que a receita do hotel aumenta de consideravelmente em relação a outras épocas do ano.

O período de baixa estação em um hotel, quando cai a taxa de ocupação, é o momento em que o meio de hospedagem procura aplicar medidas que visam a atrair o público, de modo a aumentar a sua lucratividade. Segundo Gomes (2004, s/p), "empresários usam de preços promocionais, com descontos de até $40 \%$ em suas diárias para atrair os hóspedes. [...]. Outra opção

\footnotetext{
${ }^{12}$ Taxa de ocupação é o número que indica a porcentagem dos quartos de um hotel que estão ocupados em um período. (Nota dos autores)
}

é ainda investir em divulgação para todos os brasileiros". Gomes (2004) acrescenta ainda que o poder público poderia se responsabilizar pela criação de eventos que atraíssem mais turistas e pudesse assim haver um melhor aproveitamento dos empreendimentos hoteleiros ao longo do ano. Torres (2015), por sua vez, sugere que, para combater a baixa temporada, os hotéis pratiquem ações promocionais, como descontos para aniversariantes do mês, um número maior de diárias pelo preço de um número menor, fim de semana com tarifas reduzidas, descontos no restaurante do hotel, entrega de cupons para jantares, oferecimento de brindes e amenidades especiais, promoção de serviços especiais para a terceira idade, oferta de descontos mais atrativos para universitários, divulgação do hotel para casais em núpcias, entre outras ideias.

Pode-se constatar, assim, que variadas estratégias de marketing podem ser implementadas para que os meios de hospedagem possam sobreviver a períodos de baixa estação. Por esse motivo, faz-se necessário aos estabelecimentos hoteleiros um aprofundado conhecimento de sua clientela atual, do seu público-alvo em potencial e das características relevantes de ambos os grupos. Estas podem ser sociais, étnicas, religiosas ou simplesmente comportamentais, em vistas a criar grupos com características homogêneas e prestar um serviço que venha a agradar todo aquele segmento. Com isso, até um marketing especializado pode ser utilizado para a criação de campanhas publicitárias que atraiam determinado grupo, ou grupos, em períodos considerados de menor movimento. De acordo com Dias e Cassar (2005, p.134), "ao processo de determinação de grupos de clientes com características de consumo semelhantes dá-se o nome de segmentação de mercado." Os primeiros registros a respeito desse tipo de segmentação dentro do mercado consumidor ${ }^{13}$, ou seja, da criação de grupos homogêneos desde um público heterogêneo, datam de meados de 1956. De acordo com Smith:

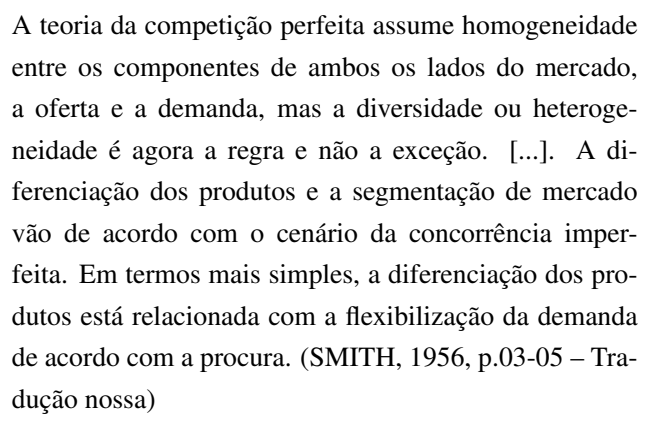

\footnotetext{
${ }^{13}$ Mercado consumidor - conjunto de pessoas existentes num determinado lugar, ou que vivem nesse lugar, e que compram e vendem produtos, mercadorias e serviços. (MIRANDA 2012.
} 
O PANORAMA DA REDE HOTELEIRA MIDSCALE DA PRAIA DE IRACEMA EM FORTALEZA-CE PARA O PÚBLICO LGBT

\begin{abstract}
Desde então, ficou estabelecida a necessidade de estudar a segmentação do mercado turístico como estratégia de marketing, visando o delineamento do perfil do consumidor. AGUIAR (2003, p.117) reforça esse fato, ao acentuar que "conhecer o perfil dos visitantes que viajam por motivos os mais diversos possíveis, é condição básica para o sucesso do planejamento e da gestão de qualquer negócio, principalmente das atividades tu-
\end{abstract} rísticas".

Segmentar nada mais é do que dividir, separar ou, para colocar definitivamente, agrupar. É possível dividir o mercado turístico partindo de variados padrões, como por exemplo, idade, sexo, poder aquisitivo, região, etc. Assim, todas essas divisões geram grupos com características comuns e ensejam uma abordagem comercial mais personalizada, como se pode constatar em Dias e Cassar (2005, p.132):

Do ponto de vista do marketing, a segmentação da demanda assume um aspecto dos mais importantes, pois permitirá a diminuição de custos e a adequação da infraestrutura do destino a um determinado públicoalvo. Com isso, evita-se a dispersão de esforços no atendimento a um público desordenado e que variará na medida em que não tenham sido atendidas as suas expectativas.

Existem diversos critérios a serem seguidos a fim de se realizar a segmentação da demanda, não apenas turística, mas para qualquer outro tipo de produto ou serviço. Devem ser considerados dois grupos de variáveis: as características do grupo e os padrões comportamentais das pessoas em relação aos produtos oferecidos (KOTLER; KELLER, 2006). A seguir, as variáveis encontram-se reunidas em um quadro, com exemplos das diferentes possibilidades de segmentação.

\begin{tabular}{|c|c|}
\hline CARACTERÍSTICAS & EXEMPLOS \\
\hline Geográficas & Fronteiras politicas; clima; fronteiras populacionais. \\
\hline $\begin{array}{l}\text { Demográficias e } \\
\text { socioeconômicas }\end{array}$ & $\begin{array}{l}\text { Sexo; idade; estado civil; composição familiar; ; educação; renda; } \\
\text { ciclo de vida familiar; ocupacăo; classe social. }\end{array}$ \\
\hline $\begin{array}{l}\text { Psicográficas } \\
\text { (de ordem psicológica) }\end{array}$ & Estilo de vida; atividades. \\
\hline PADROEES & EXEMPLOS \\
\hline Padrões de comportamento & $\begin{array}{l}\text { Momento das compras (impulso ou preferência por marcas, } \\
\text { número de unidades compradas, frequência de compras); hábitos } \\
\text { em relacão à mídia. }\end{array}$ \\
\hline Padrôes de consumo & $\begin{array}{l}\text { Frequência de uso; ocasião; fidelidade à marcas; propriedade de } \\
\text { outros produtos. }\end{array}$ \\
\hline Predisposição do consumidor & $\begin{array}{l}\text { Conhecimento do produto; beneficios buscados; problemas do } \\
\text { consumidor. }\end{array}$ \\
\hline
\end{tabular}

Quadro 2: Bases para a segmentação do mercado Fonte: Adaptado de Goeldner apud MTur. (2007)

Para definir se um segmento é atraente ou não, Frank, Massey e Wind (1972) observam alguns parâmetros bastante objetivos (Quadro 3). Segundo os autores, um grupo de pessoas poderá ser considerado de fato um segmento atraente apto à inserção e à exploração mercadológica se atender à maioria das seguintes prerrogativas:

\begin{tabular}{|c|c|}
\hline PARÁMETROS & DESCRIÇÃO \\
\hline Identificável & $\begin{array}{l}\text { Os individuos do grupo devem ser distintamente diferentes em relação a outros } \\
\text { grupos em variáveis de fácil mensuraçẫo. }\end{array}$ \\
\hline Considerável & $\begin{array}{l}\text { O grupo deve ser grande o suficiente para que seja possivel aplicar } \\
\text { investimentos junto a ele. }\end{array}$ \\
\hline Acessivel & $\begin{array}{l}\text { O grupo deve ser acessível através de estratégias de marketing, propaganda e } \\
\text { esforços de distribuiçẫo. }\end{array}$ \\
\hline Estável & Deve ser um grupo que persista ao longo do tempo. \\
\hline Receptivo & Como segmento, o grupo deve responder aos esforços direcionados a ele. \\
\hline Acionável & $\begin{array}{l}\text { Um programa efetivo de marketing poderá ser facilmente elaborado parao } \\
\text { segmento. }\end{array}$ \\
\hline
\end{tabular}

Quadro 3: Parâmetros para segmentação

Fonte: Adaptado de Frank, Massey e Wind (1972)

Sendo assim, é possível se detectar distintos segmentos dentro do mercado turístico atual. Apenas como exemplo tem-se o turismo de negócios, o turismo de eventos, o turismo religioso, o turismo rural, o ecoturismo, o turismo cultural, o turismo para a terceira idade, o turismo de compras e o turismo LGBT, que é alvo de estudo do presente trabalho.

O segmento LGBT é bem diferente de outros segmentos de mercado, como o dos idosos ou o do consumidor infantojuvenil, por exemplo, pois geralmente não possui uma característica física de fácil identificação e não pode ser definido, pois, por uma análise visual. De acordo com Reinaudo (2008), o público LGBT muda de tamanho conforme a aceitação da sociedade onde está inserido. Por conta disso, os autores consideram como público LGBT propriamente dito aqueles que aceitam com naturalidade sua orientação sexual e incluem, principalmente no Brasil, os simpatizantes, ou seja, as pessoas ligadas aos homossexuais de modo afetivo ou ideológico e que também são potenciais consumidores

\section{O SEGMENTO LGBT}

O termo "homossexualidade" teve origem no campo da Medicina e foi introduzido, segundo Vidal (1998, p.07), "por um médico húngaro no século XIX. Apesar da sua conotação clínica inicial, passou a significar a realidade humana total daquelas pessoas, cujo impulso sexual se orienta para pessoas do mesmo sexo".

A homossexualidade é, conforme expresso em Reinaudo (2008), apenas uma das opções naturais da orientação sexual. Homossexual é aquele ou aquela cujo impulso sexual é direcionado a uma pessoa do mesmo sexo. Por conseguinte, as demais opções são a bissexualidade - quando esse impulso se dá tanto para pessoas do mesmo sexo como do sexo oposto - e a heterossexualidade, quando a atração sexual se dá apenas por pessoas do sexo oposto.

Ponto importante a ser tratado quando se fala sobre o segmento LGBT, é considerar que ser gay, lésbica, travesti, transexual, bissexual ou qualquer um desses 
"rótulos" existentes, é mais do que uma questão meramente sexual. O consumidor LGBT possui toda uma cultura, um estilo de vida, o que torna este um segmento individualizado.

Naturalmente, a vida dos gays não é simplesmente definida pela sua sexualidade, mas sim pela sua classe social, sexo, raça, idade e habilidade também, todas as variáveis que influenciam as decisões dos consumidores e que, em qualquer caso, serão influenciadas pelo ambiente sociopolítico em que vivem. No entanto, os consumidores homossexuais têm sido identificados como um segmento de mercado significativo e isso se tornou especialmente evidente no mundo das viagens e do turismo. (JORDAN, 2012, p.10 - Tradução nossa).

Guinoza (2011, s/p) informa que, no que concerne ao público LGBT, “a maior parte preza a sofisticação e o conforto e, por isso, não se incomoda em pagar mais, desde que o produto ou serviço seja de qualidade". Ainda de acordo com Guinoza (2011, s/p), "de modo geral, gays também são mais sociáveis, saem mais de casa e, por consequência, gastam mais". Pode-se observar um exemplo de outra característica particular do público LGBT:

O segmento gls tem ainda outra característica que o diferencia de outros segmentos. O próprio fato de homossexuais estabelecerem relações com pessoas do mesmo sexo faz com que não tenham filhos, ou ao menos não os tenham sem que decidam por isso. Daí ocorre [...] a tendência a serem DINKs (Double Income No Kids, dupla renda sem filhos) e por consequência sempre terem um poder aquisitivo acima da média. (REINAUDO, 2008, p.76)

As preferências específicas desse público são bem peculiares, e, se forem devidamente estudadas e analisadas de forma estratégica, podem conferir ao meio de hospedagem retorno nos investimentos, uma vez que é um segmento grande em número de pessoas. Em geral, o consumidor LGBT tem preferência por serviços de qualidade, com certo requinte. Porém, o diferencial na hora de conquistar a fidelidade dessa clientela, além de garantir toda a qualidade do serviço, é prezar por um bom atendimento. Como exemplo dessa preocupação, a Associação Abrat - GLS realiza cursos de capacitação e workshops para desenvolver, junto aos meios de hospedagem, técnicas de como receber o público LGBT de maneira eficiente, evitar constrangimentos e abolir os "pré-conceitos", muitas vezes intrínsecos aos funcionários.

De acordo com Moraes (2009), os hotéis do Recife recebem um selo indicativo de "Hotel Gay-Friendly", após terem aplicado junto a seus funcionários um treinamento especial, o que significa que naquele estabe- lecimento o público LGBT será bem recebido e bem tratado. Esta iniciativa é do Recife Convention \& Visitors Bureau (RC\&VB). Foi declarado também que há folhetos informativos nos hotéis com opções de passeio indicados pelo próprio $\mathrm{RC} \& \mathrm{VB}$.

$\mathrm{O}$ reconhecimento de gays e lésbicas como um segmento de mercado, não aconteceu da noite para o dia. $\mathrm{O}$ histórico de preconceito e discriminação, sofridos pelos gays e lésbicas, é um grande obstáculo para o segmento.

De acordo com Reinaudo (2008), os primeiros movimentos nesse sentido tiveram início em um bar chamado Stonewall Inn, na noite de 28 de junho de 1969 , em Greenwich Village, na cidade de Nova Iorque, quando gays, lésbicas e travestis frequentadores do bar foram intimidados durante uma das batidas policiais que eram feitas costumeiramente no local, e que na maioria das vezes resultavam em algumas detenções. Naquela época, a homossexualidade era punida e reprimida, mas, nessa noite, os clientes do bar não se permitiram ser ameaçados, exibindo uma mudança de comportamento, e tal resistência permaneceu durante dias. O fato repercutiu mundialmente nas comunidades LGBT e ficou conhecido como a Revolta de Stonewall, o que fez com que o dia 28 de junho ficasse conhecido como o Dia Internacional do OrgulhoGay.

Nos dias de hoje, ainda resta muita intolerância para com esse público. Para os membros do público LGBT, tais pensamentos representam um grande retrocesso. Atitudes discriminatórias advindas de qualquer parte interferem na aceitação e em investimentos juntos a esse nicho de mercado. Segundo um estudo do Banco Mundial (2014 ${ }^{14}$ o custo da exclusão das minorias sexuais para as sociedades ultrapassa bilhões de dólares todo ano.

No Brasil, de acordo com Hughes (2016) da Out Leadership ${ }^{15}$, o potencial financeiro do segmento LGBT é estimado em US\$ 120 bilhões, ou quase $10 \%$ do PIB nacional. Conforme o censo ${ }^{16}$ do IBGE (2010), existem no Brasil mais de 67 mil casais formados por pessoas do mesmo sexo. A população homossexual no País é estimada em 20 milhões de habitantes.

Apesar desses números impressionantes, ainda há pouco investimento e capacitação da rede hoteleira para

\footnotetext{
${ }^{14} \mathrm{O}$ Grupo Banco Mundial (Banco Internacional para a Reconstrução e Desenvolvimento - BIRD), é um órgão ligado ao Sistema das Nações Unidas. É a maior fonte global especializada em assistência para o desenvolvimento, reduzindo pobreza e desigualdade por meio de empréstimos e doações aos 187 países-membros. (Nota dos autores)

${ }^{15}$ Out Leadership - Associação internacional de empresas que desenvolve iniciativas para o público gay.

${ }^{16}$ Último censo realizado pelo IBGE - Instituto Brasileiro de Geografia e Estatística - e primeiro a contabilizar casais residentes do mesmo sexo. (Nota dos autores)
} 
atender esse público de maneira satisfatória. Chiesa (2016) relata que ainda falta interesse das cidades brasileiras em fidelizar este segmento de mercado, pois faltam investimentos na capacitação do trade turístic ${ }^{17}$ no apoio a eventos LGBT e na promoção dos destinos como "friendly".

No entanto, este quadro se mostra de maneira diferente no cenário internacional. Carvalho (2013) aponta hotéis internacionais que investem quase que exclusivamente no segmento LGBT, a saber, o resort americano The Out NYC, o hotel Axel em Barcelona e o hotel Lords South Beach em Miami. Esses poucos exemplos de iniciativas tomadas no mundo mostram o retorno mercadológico dos investimentos no público LGBT. Tais iniciativas poderiam ser adaptadas para a realidade brasileira, de maneira que essas ideias viessem a ser incorporadas às propostas oferecidas pelos meios de hospedagem do País.

\section{RESULTADOS E DISCUSSÕES}

Expõem-se aqui os resultados da pesquisa realizada junto a 20 hotéis de categoria midscale localizados na Praia de Iracema em Fortaleza, Ceará, onde apenas 14 estabelecimentos retornaram com resultados. As respostas fornecidas às nove perguntas foram analisadas quantitativamente, por meio do número de hotéis ou porcentagem; e qualitativamente, por meio de posicionamentos baseados nos pressupostos teóricos.

A respeito do conhecimento do meio de hospedagem sobre o potencial de consumo LGBT, 11 hotéis não consideraram que exista diferença de consumo entre o público LGBT e o público de outros segmentos. Outros 2 estabelecimentos reconheceram esse público como possuidor de um alto potencial de consumo, mas, ainda assim, admitiram não haver investido ainda no segmento. Apenas 1 dos hotéis pesquisados afirmaram se preocupar com o poder do "pink money". Isso mostra que existe considerável falta de conhecimento da parte dos meios de hospedagem pesquisados em relação a esse nicho de mercado e suas características. Como consequência, se não houver investimentos na área, o reflexo será uma perda de oportunidades para esses meios de hospedagem.

O público LGBT frequentemente procura ambientes gay friendly para se hospedar quando vão viajar. Com base nisso, foram buscadas informações a respeito da identificação do hotel como gay friendly, através de uma placa, um selo indicativo, ou com outra indicação. Nenhum dos hotéis entrevistados possuía algum tipo de

\footnotetext{
${ }^{17}$ Trade turístico - conjunto de organizações que constituem o produto turístico, atuando nos setores de turismo e eventos. (Nota dos autores)
}

identificação para o público em questão. A justificativa dada por 9 hotéis foi de que eles não se identificavam como gay friendly porque promoviam atendimento igual para qualquer segmento de mercado. $\mathrm{O}$ assunto ainda não havia sido ponderado por 2 hotéis, mas os mesmos admitiram que não haveria problema em uma futura identificação. Enquanto que outros dois estabelecimentos informaram que se identificariam e que já ocorreram algumas discussões a respeito. Mais uma vez, apenas um hotel informou que não se identificava com o termo, pois isso poderia afastar outros clientes.

Os números acima demonstram que em quase $86 \%$ dos hotéis participantes da pesquisa ocorre uma não aceitação aberta da identificação do empreendimento como gay friendly. E mesmo a parcela de pouco mais de $14 \%$ onde já se levanta a questão, ainda não foi tomada nenhuma medida efetiva para essa identificação. Sendo assim, é imprescindível um trabalho conjunto de órgãos públicos e privados que lidam com hotelaria para a conscientização e mudança de atitude para com esse nicho mercadológico para um melhor aproveitamento dos recursos possíveis e uma diminuição da sazonalidade hoteleira percebida em vários períodos do ano.

Quanto ao cadastramento em sites de turismo LGBT, foi informada no questionário a existência de diversas agências de viagem e sites de turismo especializados para esse público. Alguns meios de hospedagem possuem cadastro nesses sites/agências e são indicados como destino para quem está disposto a fazer turismo. Porém, 6 dos hotéis pesquisados admitiram que não se cadastrariam, pois prefeririam o cadastro em sites de agências de turismo que atendem ao público em geral, independentemente da segmentação. Entre os hotéis pesquisados, 4 possuíam cadastro em agências de turismo LGBT e outros 4 afirmaram que se cadastrariam, mas tal assunto ainda não havia sido ponderado até o momento da pesquisa. A padronização no atendimento, mais uma vez, é evidenciada e confirma o fato de que não é costumeiro o investimento na segmentação de mercado turístico LGBT pelos hotéis midscale da Praia de Iracema. A preferência pela não vinculação da marca do estabelecimento hoteleiro em sites de utilização frequente pelo público LGBT é a característica mais marcante e atual.

Outra informação buscada foi a existência de material de divulgação específico para o público LGBT dentro dos estabelecimentos. Uma pequena parcela, 2 dos hotéis pesquisados, possuíam material de divulgação direcionado para atrair o público LGBT, sendo que esse material estava disponibilizado apenas na Internet. Os outros 12 hotéis trabalhavam com material padronizado para qualquer que fosse o segmento de mercado, 
sem fazer diferenciações. Sendo assim, houve indicação clara da inexistência de projetos de marketing e propaganda na maioria dos hotéis com o intuito de atrair a atenção de segmentos turísticos.

Quanto ao tópico de formação ou treinamento de staff, verificou-se que metade dos hotéis consultados achava ser desnecessário que os funcionários recebessem algum treinamento direcionado ao atendimento do público LGBT. O conceito era interessante para 5 dos estabelecimentos, mas não havia ainda investido em capacitações nesse sentido. Apenas 2 estabelecimentos afirmaram que seus funcionários receberam treinamento específico para o atendimento do público LGBT. Pode-se verificar, por meio desses dados, que a maior parte dos meios de hospedagem pesquisados não investe em qualificação profissional em relação a esse segmento. Tendo em vista a amplitude da concorrência no ramo hoteleiro de Fortaleza, uma qualificação profissional voltada ao gerenciamento do público LGBT pode fazer diferença no momento da escolha por um lugar para se hospedar, como também na sensação de hospitalidade percebida pelos clientes, que podem não se sentir acomodados adequadamente através de algum ato discriminatório.

Quando indagados sobre informações a respeito de estabelecimentos LGBT, os funcionários de 8 dos hotéis pesquisados admitiram possuir conhecimento de lugares a serem indicados sem distinção de público. Uma parcela menor, funcionários de 4 hotéis, se utilizavam de ferramentas de pesquisa, como a Internet, para dar informações no momento em que essas são solicitadas, pois afirmaram não possuir conhecimentos de lugares GLS. Somente 2 hotéis acentuaram que seus funcionários são capacitados para informar o público LGBT com espontaneidade sobre os melhores estabelecimentos GLS da cidade. Mais uma vez, ficou a indicação que a maioria dos estabelecimentos hoteleiros pesquisados não estava preparada para atender conscientemente o público em questão.

Buscou-se também descobrir se os meios de hospedagem promoviam ou já promoveram ações para captação do público LGBT durante a Parada Gay de Fortaleza, que acontece na Avenida Beira-Mar e recebe cerca de 500 mil pessoas oriundas de diversos lugares do Brasil e do mundo. Mesmo com esses dados, nenhum hotel consultado realizava ações regulares anuais para captar o público LGBT para o evento. Uma minoria de 2 hotéis afirmou que ações esporádicas já foram realizadas. Os outros 12 hotéis verificados afirmaram que não promoveram ações a fim de captar esse público porque a procura ocorria naturalmente. Essa constatação expôs a falta de interesse dos hotéis midscale da
Praia de Iracema em, para esse evento em específico, se engajar em campanhas especiais para atrair um público comprovadamente rentável. Nesse caso, um bom plano de ação para captar o público LGBT poderia fazer a diferença no aumento da receita dos hotéis durante o evento, como também aumentar a chance de fidelização dos hóspedes pelo bom acolhimento e atendimento prestados em uma possível primeira experiência.

Mediante um exemplo prático hipotético foi analisado, ainda, o comportamento dos hotéis em relação aos hóspedes LGBT: dois homens ou duas mulheres têm uma reserva onde consta um apartamento com uma cama de casal. Foi questionado, então, qual o procedimento adotado durante a recepção desses hóspedes. Ante tal situação específica, bastante comum nos meios de hospedagem em geral, 12 dos estabelecimentos hoteleiros realizavam a recepção normalmente, apenas confirmando no ato do check-in com as/os hóspedes os detalhes das reservas, inclusive a questão da opção das camas. Somente 2 dos hotéis afirmaram que o setor de reservas estava orientado para colher estas informações no momento em que a reserva fosse efetuada. Nenhum hotel informou alterar deliberadamente a reserva para camas de solteiro antes da chegada dos hóspedes.

O exemplo exposto representa um momento delicado, em que qualquer informação dada ou questionamento solicitado pode causar constrangimento aos hóspedes, sejam eles gays ou não. $\mathrm{O}$ ideal seria que a informação já viesse pronta desde o momento da reserva. Porém, constatou-se que apenas 2 dos hotéis consultados adotavam esse procedimento. Deixar para fazer esses esclarecimentos apenas durante o recebimento dos hóspedes, como a maioria dos hotéis afirmou fazer, pode tornar o atendimento deveras impessoal e ocasionar a perda de uma oportunidade para cativar e fidelizar o cliente.

Um dos itens da pesquisa buscava avaliar o posicionamento dos meios de hospedagem quanto à segmentação mercadológica em geral. Verificou-se que 13 dos hotéis midscale pesquisados da Praia de Iracema não trabalhava com segmentação de mercado, seja ela qual fosse. Assim, a recepção dos diversos tipos de clientes se dava de uma maneira padronizada. Entendeu-se que a busca por um atendimento eficiente, na visão da maioria dos hotéis pesquisados, estava relacionada à padronização dos procedimentos de reservas, recepção e vendas, uma vez que não se buscava a adaptação e personalização do atendimento para os diversos tipos de demanda.

Mediante o apanhado dessas informações, ficou evidente a desatenção dos hotéis midscale da Praia de Iracema para o segmento LGBT e notou-se ainda uma 
falta de estratégias de marketing voltadas à personalização do atendimento. Percebeu-se ainda que a maioria dos meios de hospedagem envolvidos nessa pesquisa não reconhece o público em questão como um real segmento de mercado, desconhecendo seu potencial de consumo e subestimando, assim, uma segmentação de mercado em potencial.

\section{CONSIDERAÇÕES FINAIS}

Este é um trabalho que trata, em sua essência, sobre segmentação de mercado e marketing, assuntos indubitavelmente ligados à economia e ao comércio. Tal pesquisa poderia girar em torno de qualquer segmento extraído do mercado hoteleiro, como o grupo da terceira idade, o grupo de jovens viajantes ou o grupo corporativo. A linha de raciocínio para se estudar cada segmento teria sido a mesma utilizada para a exploração do segmento LGBT.

O público-alvo escolhido para o estudo, porém, trouxe dificuldade para o andamento da pesquisa ao se verificar que em certos momentos os entrevistados tendiam a sair do foco econômico e comercial desejado. Quando se fala em gays, lésbicas, travestis, transexuais, bissexuais e toda a gama de variações da sexualidade humana surge normalmente uma inclinação, naqueles que estão como expectadores, de encarar a situação com uma conotação cômica ou preconceituosa.

Por diversas vezes a relevância desta pesquisa foi colocada em dúvida. Afinal, se todos merecem ser tratados como iguais, por que criar uma diferenciação de um grupo de pessoas simplesmente por sua orientação sexual? Ao ser realizado um trabalho sobre o público LGBT, não se estaria promovendo a segregação daquele grupo de pessoas? Ora, segregar não é o mesmo que segmentar. Enquanto o termo segregação está ligado à ideia de exclusão de um determinado grupo de pessoas em detrimento de outro ou outros, o vocábulo segmentação, como explicado em uma das seções deste trabalho, está relacionado a uma ideia oposta a essa. Segmentar é agrupar, é partir de um conjunto de elementos diferentes e reorganizá-los de modo que se possa ver cada novo grupo mais claramente, por meio daquilo que eles têm de semelhante em sua maneira de se comportar. Sendo assim, valorizar o segmento LGBT - ou qualquer outro - é criar laços mais próximos com essa clientela, adaptando-se ao seu comportamento e melhor atendendo suas expectativas comerciais.

Foram encontradas as respostas para os três questionamentos levantados no início desse artigo. Sobre a ciência dos hotéis midscale da Praia de Iracema a respeito da possibilidade de lucro ao investir no segmento LGBT, concluiu-se que a maioria dos hotéis dentro do universo desse levantamento não trabalhava com segmentação turística, nem do público LGBT. Portanto, não havia ciência do poder desse nicho de mercado formado pelos gays, lésbicas e simpatizantes. O público LGBT é altamente promissor e poderia, se bem explorado, aumentar consideravelmente a sua lucratividade.

Foi verificado que não existiam, nos meios de hospedagem pesquisados, hotéis que se intitulavam "gay friendly" e nenhum possuía algum selo, placa ou identificação para tal fim. A justificativa para isso foi sempre a preferência pela padronização - o meio de hospedagem procurava não fazer diferenciação no atendimento de seus hóspedes. A princípio, tal afirmação parecia politicamente correta, mas estava na contramão da estratégia da segmentação turística mostrada neste trabalho.

Quanto aos fatores que poderiam dificultar o investimento dos hotéis no segmento LGBT, a resposta esteve nas justificativas fornecidas pelos hotéis para não se identificar como "gay friendly". A questão da padronização existia e era a opção da maioria. Os hotéis pesquisados não haviam mensurado ainda a diferença de consumo entre outros públicos e o segmento LGBT, com isso, não se cadastrariam em sites e agências de viagens especializados nesse público, os funcionários não haviam sido treinados para informar esse público a respeito dos lugares GLS da cidade, não faziam ações para atrair o segmento. Foi notória, pois, a ignorância e indiferença em relação ao público-alvo da pesquisa, embasada na falta de conhecimento a respeito do poder do "pink money" e na busca de uma padronização no atendimento que pode vir a ser danosa para o próprio meio de hospedagem.

Então, o objetivo principal deste trabalho foi alcançado, pois, foi traçado um panorama sobre o posicionamento da rede hoteleira midscale da Praia de Iracema em relação ao marketing aplicado junto ao segmento LGBT. A maioria dos hotéis pesquisados não expressou interesse ou engajamento para realizar investimentos junto a esse público e não existiam planos de marketing nos hotéis dessa região para atingir esse segmento.

Ainda há muitas barreiras a serem quebradas e muitos tabus a serem superados. A conscientização da importância da exploração dos diversos segmentos de mercado, possibilitada pela variação de consumidores existentes, é mister para a diminuição da sazonalidade hoteleira de qualquer destino turístico e é um fator contemporâneo mundial que não pode mais ser ignorado.

\section{REFERÊNCIAS}

AGUIAR, M. d. F. Turismo, Cultura e Identidade. São Paulo: Rocca, 2003. 
Banco Mundial. The Economic Cost of Homophobia: how LGBT exclusion impacts development. Produção: The World Bank. 2014. Disponível em: <http://live.worldbank.org/ economic-cost-of-homophobia $>$

CALFAT, C. Apesar da desaceleração da economia, setor hoteleiro ainda tem espaço para investimentos - desde que sejam bem planejados, avalia consultor. 2014. Disponível em: <https://goo.gl/3Nr7Rf>

CARVALHO, L. Os melhores hotéis para o público gay, segundo site Trivago. 2013. Disponível em: <https://goo.gl/idVe6m>

CHIESA, M. D. Falta investimento e interesse para fidelizar o turista gay. 2016. Disponível em: <https://goo.gl/zSQ3WC>

COBRA, M. Administração de Marketing no Brasil. Rio de Janeiro: Elsevier, 2009.

CUNHA, L. Economia e política do turismo. Lisboa: McGraw Hill, 1997.

DIAS, R.; CASSAR, M. Fundamentos do Marketing Turístico. São Paulo: Pearson Prentice Hall, 2005.

FACCHINI, R. Sopa de Letrinhas? Movimento Homossexual e Produção de Identidades Coletivas nos anos 1990. Rio de Janeiro: Garamond, 2005.

FISCHER, A. Antigamente os personagens gays das novelas morriam em explosão de shopping. 2007. Disponível em: <http://portalimprensa.com.br/revista/ edicao_mes.asp?idEdicao=6\&idMateriaRevista=71>.

FRANK, R. E.; MASSEY, W. F.; WIND, Y. Market Segmentation. [S.1.]: Prentice Hall, 1972.

FREITAS, E. L. de; SILVA, J. S. S. e. Educação tecnológica: teoria e prática do turismo, da hospitalidade e do lazer. [S.1.]: Expressão gráfica e editora, 2011.

FUNDAÇÃO CTI/NE. Relatório de Competitividade 2014. Conjuntura do Desempenho do Turismo no Nordeste: 2002/11. 2014. Disponível em: <http: //www.ctinordestedobrasil.com.br/estatisticas.html>

FURBINO, M. Melhoria Contínua. 2010. Disponível em: <http://www.revistaportuaria.com.br/colunas/ 539>

GOMES, I. B. Sazonalidade no Turismo, o que fazer na baixa temporada? 2004. Disponível em: <http://www.revistaturismo.com.br/artigos/ sazonalidade.html $>$
GUINOZA, M. O poder do pink money. 2011.

Disponível em: <http://brasileiros.com.br/5MihM>

Hartmut Sangmeister, S. M.; STECKBAUER, S. C. O Brasil na América Latina. São Paulo: Annablume, 2007.

HUGHES, D. Todd Sears: os Jogos Olímpicos são uma oportunidade histórica para empresas no Brasil a demonstrar a inclusão LGBT. 2016. Disponível em: <https://goo.gl/2MU2tf>.

IBGE. Censo 2010. 2010. Disponível em: <http://www.ibge.gov.br/home/estatistica/ populacao/censo2010/caracteristicas_da_populacao/ caracteristicas_da_populacao_tab_brasil_zip_ods. shtm>

Pesquisa de Serviços de Hospedagem. 2011

Disponível em: <http://www.ibge.gov.br/home/ estatistica/economia/comercioeservico/psh/2011/>

JORDAN, P. The social impact of lgbt tourism: why welcoming lgbt travellers is not just good for business. In: WORLD TOURISM ORGANIZATION. Global Report on LGBT Tourism. Madrid, 2012.

KOTLER, P. Administração de Marketing: a edição do novo milênio. São Paulo: Prentice Hall, 2000.

KOTLER, P.; KELLER, K. L. Administração de Marketing. [S.1.]: Pearson Prentice Hall, 2006.

MIRANDA, M. B. Revista Virtual Direito Brasil, v. 6, n. $31,2012$.

MORAES, R. Recife cria selo "friendly"para atrair turistas gays. 2009. Disponível em: $<$ http://www1.folha.uol.com.br/turismo/2009/02/ 507218-recife-cria-selo-friendly-para-atrair-turistas-gays. shtml>

MOTA, K. C. N. Egressos do curso de hotelaria do Instituto Federal do Ceará: perfil, satisfação e relação com o mercado. 2011. 21-45 p.

MTUR. Programa de Regionalização do Turismo - Roteiros do Brasil: Módulo Operacional 8: promoção e apoio à comercialização. Brasília: Brasil. Ministério do Turismo, 2007.

Segmentação do Turismo e o Mercado.

Brasília: Brasil. Ministério do Turismo, 2010.

Turismo mundial registra recorde de viajantes em 2014. 2015. Brasil. Ministério do Turismo. Disponível em: <http://www.brasil.gov.br/turismo/2015/01/ turismo-mundial-registra-recorde-de-viajantes-em-2014> 
. Mais de mil obras de Turismo são entregues em 2016. 2016. Brasil. Ministério do Turismo. Disponível em: <http://www. turismo.gov.br/\%C3\%BAltimas-not\%C3\%ADcias/ 7243-turismo-entrega-mais-de-mil-obras-em-2016. html>.

NUCCI, D. O poder do pink Money. 2014. Disponível em: <http://metropole.rac.com.br/_conteudo/2014/ 04/capa/leia_mais/172176-o-poder-do-pink-money. html>.

O POVO. Fortaleza o é quarto destino mais procurado. 2014. Disponível em: <http:

//www.opovo.com.br/noticias/economia/2016/12/

fortaleza-e-quarto-destino-mais-procurado-no-tripadvisor. html>.

REINAUDO, F. Mercado GLS: como obter sucesso com o segmento de maior potencial da atualidade. São Paulo: Matrix, 2008.

SMITH, W. R. Product differentiation and market segmentation as alternative marketing strategies. Journal of Marketing, v. 21, n. 1, p. 3-8, Julho 1956.

TANKE, M. L. Administração de recursos humanos em hospitalidade. São Paulo: Thomson, 2005.

TORRES, M. Dicas de promoções para hotéis, pousadas e flats - Marketing Hoteleiro. 2015. Disponível em: <http://marketinghoteleiro.com/ dicas-de-promocoes-para-hoteis-marketing-hoteleiro>

TULESKI, Y. M. Tutorial - Segmentação de Mercado. [S.1.], 2009.

VIDAL, M. Homossexualidade: ciência e consciência. São Paulo: Edições Loyola, 1998.

YAARI, A. Combate a Sazonalidade. 2010. Disponível em: <http://www.revistahoteis.com.br/ combate-a-sazonalidade/ $>$. $>$ 